\title{
Is Malnutrition Most Associated with Dynamic or Static Physical Performance?
}

\author{
(D) Şenay Günaydın \\ Istanbul University, Internal Medicine/Geriatrics, İstanbul, Turkey
}

\begin{abstract}
Objective: Malnutrition is a state resulting from lack of uptake or intake of nutrition that leads to altered body composition, decreased fat-free mass and body cell mass. Its prevalence varies according to health conditions and the level of care dependency. The prevalence in individuals over 65 years of age attending outpatient clinics varies in 9\% to 15\%. Malnutrition can be associated with decreased physical and mental function and impairment of body cell components. Decreased physical capacity causes shortened mobility and difficulties in daily activities such as shopping, cooking, eating, etc. Malnutrition and decline in functional status are two important factors contributing to loss of independence. The aim of this work was to describe the association between nutritional and functional status.

Materials and Methods: This retrospective study included 406 patients aged 60 and older who were referred to the geriatric outpatient clinic at Istanbul University Istanbul Medical Faculty. The nutrition status was determined using the Mini Nutritional Assessment-short form (MNA-SF, cut off $\leq 11$ ) including six questions specific to diet and anthropometric measurements. The total score can be as high as 14 points. A score of 12 to 14 signifies normal nutritional status and 11 or lower indicates possible malnutrition. Both dynamic and static functional status were evaluated. Measures of dynamic physical performance included the Timed Up and Go test (TUG), Gait Speed test, and Chair Stand test (CST). Static performance was determined by balance tests and hand grip strength (HGS). Linear regression analysis was used to study the association between malnutrition with physical performance.
\end{abstract}

Results: The study sample comprised 406 participants with the mean age of $74.8 \pm 6.7$ years. $69.7 \%$ were female and $30.3 \%$ were male. Malnutrition was found in $28.8 \%$ of the patients ( $n=117)$. Malnutrition was found most strongly associated with $\mathrm{HGS}(\mathrm{p}<0.018)$ and less strong with Balance test $\mathrm{p}=0.046$. There was no significant association between TUG, CST, gait speed and two components of Balance test.

Conclusion: Malnutrition is an important problem which could result in diminished physical and mental function in older people. In our study, malnutrition defined by the MNA-SF was associated with physical performance tests, especially HGS, which is an indicator of static physical performance rather than dynamic functionality measures. MNA-SF might be a useful screening tool as a surrogate marker of functional status, especially if a specific functionality testing cannot be applied.

Keywords: Malnutrition, physical performance, Static and Dynamic test

\section{Introduction}

Malnutrition has been defined as "a state, resulting from lack of uptake or intake of nutrition that leads to altered body composition (decreased fat free mass) and body cell mass leading to diminished physical and mental function and impaired clinical outcome from disease" and this definition is synonymous with undernutrition (1). New criteria for diagnosis of malnutrition were introduced in 2018 from the Global Leadership Initiative on Malnutrition. The criteria require the combination of at least one phenotype and one etiologic feature (2). Screening tools for malnutrition include measuring weight, calculating weight loss, and other questionnaires. Mini Nutritional Assessment (MNA) is one of the screening tools that include questions specific to diet and anthropometric measurements.

Address for Correspondence: Şenay Günaydın, İstanbul University, Internal Medicine/Geriatrics, İstanbul, Turkey Phone: + 902124142000 E-mail: senay.gunaydin@istanbul.edu.tr ORCID: orcid.org/0000-0002-3274-4827

Received: May 31, 2020 Accepted: Jul 10, 2020

Cite this article as: Günaydın Ş. Is Malnutrition Most Associated with Dynamic or Static Physical Performance? Eur J Geriatr Gerontol 2020;2(2):53-57

๑Copyright 2020 by the Academic Geriatrics Society / European Journal of Geriatrics and Gerontology published by Galenos Publishing House. 
Malnutrition is accompanied by loss of body weight, muscle mass and strength (3) that is common in older individuals and may have greater impact on outcomes such as physical function (4). Muscle mass is a key linking substrate between malnutrition and physical performance. Either malnutrition and poor physical function may be highly interrelated and may potentiate each other. Assessment of the physical function of the older people has importance in clinical risk evaluation (5). There are some different ways of determining both the dynamic and static physical functions. Dynamic physical performance measures include tests of Timed Up and Go test (TUG), gait speed (4-m walk test), and Chair Stand test (CST). Static performance measurements include balance test (side-by-side, semi-tandem, and full tandem stand) and hand grip strength (HGS).

In this study, we aimed to evaluate the malnutrition status and its correlation with dynamic and static physical performance among older patients presented to our outpatient clinic, due to the increasing prevalence of malnutrition and lack of studies assessing these factors in the Turkish community.

\section{Materials and Methods}

\section{Study Design}

This retrospective study included 406 community dwelling older patients aged $\geq 60$ who were referred to Istanbul University's geriatric outpatient clinic from January 2018 to January 2020. The study has been approved by Istanbul University, Istanbul Medical Faculty, Ethical Committee (approval no: 90767, date: 06.06.2020).

\section{Measurement of Nutritional Status}

MNA has two parts - short and total form. The total form consists of 18 questions in five sub-categories. Functionality, general assessment, anthropometry, dietary assessment and subjective assessment are evaluated in these tests (6). Previous study revealed that short form MNA (MNA-SF) was strongly correlated with the total MNA score. In this study the presence of malnutrition status was determined by using MNA-SF (7). The MNA-SF consists of six questions related to acute disease, neuropsychological problems, body mass index, weight loss, mobility and decline of food intake. According to the short form score (0-14 points) the subjects are classified as well nourished ( $>11$ points), at risk of malnutrition (8-11 points) and malnourished (0-7 points). In this study poor nutrition status was defined as scores $\leq 11$ points in MNA-SF.

\section{Performance Status}

Measurement of both dynamic and static physical performance were evaluated. Measures of dynamic physical performance included TUG, 4-m Walk test and CST. Static performance was determined by Balance tests and HGS. As TUG test measures the patient's time while they stand up from a chair, walk three meters, return to the chair and sit down again (8). The cut off score was $\geq 20$ sn. To determine $4-m$ walk test, patients were instructed to walk at their comfortable speed. To avoid of slowing patient down walking distance exceeded the required four meters. The time they reached at 4 meters was expressed as $\mathrm{m} / \mathrm{s}$. To perform CST test patient were told to fold their arms across their chest and try to stand up once from a chair for 5 repeats. The total time that required to perform five rises was measured.

Handgrip strength was measured by Jamar hydraulic hand dynamometer. The patients were instructed to squeeze the tool with whole strength three times with each hand, the maximum score was used for analyses. Values $<27 \mathrm{~kg}$ for men and $<16 \mathrm{~kg}$ for women were classified as weak. Other test for measuring static analyzes was Balance test. Balance test recorded as side by side, semi-tandem, and tandem.

\section{Statistics}

The characteristics of the participants were described. When data were distributed normally continuous variables were presented as mean and standard deviation. Dichotomous variables were reported by the number (n) and percentage (\%). Linear regression analysis was used to study the association between malnutrition with both dynamic and static measures of physical performance. Results for the linear regression analysis are presented as beta, or for the logistic regression as odds ratios, and 95\% confidence intervals with $p$ values.

For all statistical analyses, SPSS version 21.0 program were used. A p value of less than 0.05 was considered as statistically significant.

\section{Results}

This study included 406 geriatric outpatients [283 (69.7\%) women and 123 (30.3\%) men]. The mean age of the participants was $74.8 \pm 6.7$. Characteristics of the patients are shown in Table 1.

More than half of the participants $(71.2 \%)$ had a normal nutritional state but $28.8 \%(n=117)$ suffered from malnutrition or were at risk of malnutrition. The measures of both dynamic and Statics test are shown in Table 2.

Table 3 shows the correlation between malnutrition based on MNA-SF and measures of different physical performance. Malnutrition was most strongly associated with HGS $(p<0.018)$ and Balance test (tandem) $(\mathrm{p}<0.046)$.

\section{Discussion}

The purpose of this study was to compare the associations between malnutrition and risk of malnutrition based on 
MNA-SF questionnaire; and dynamic and statics physical performance measures in geriatric outpatients. We use TUG test, 4-m Walk test and CST as dynamic physical measures and

\begin{tabular}{|c|c|c|}
\hline Measure & Total $(n)=406$ & SD \\
\hline $\begin{array}{l}\text { Age, mean } \\
\text { Female } \\
\text { Male }\end{array}$ & $\begin{array}{l}74.8 \\
74.3(\min =61-\max =91) \\
76(\min =62-\max =90)\end{array}$ & $\begin{array}{l}6.7 \\
6.8 \\
6.5\end{array}$ \\
\hline $\begin{array}{l}\text { Gender }(\mathrm{n}) \\
\text { Female }(\%) \\
\text { Male }(\%)\end{array}$ & $\begin{array}{l}283(69.7) \\
123(30.3)\end{array}$ & $\begin{array}{l}- \\
-\end{array}$ \\
\hline $\begin{array}{l}\text { BMI }\left(\mathrm{kg} / \mathrm{m}^{2}\right) \\
\text { BMI female }\left(\mathrm{kg} / \mathrm{m}^{2}\right) \\
\text { BMI male }\left(\mathrm{kg} / \mathrm{m}^{2}\right)\end{array}$ & $\begin{array}{l}30.2(\min =13.3-\max =58.7) \\
31.2(\min =13.4-\max =58.7) \\
27.9(\min =13.3-\max =40.2)\end{array}$ & $\begin{array}{l}5.8 \\
6 \\
4.5\end{array}$ \\
\hline $\begin{array}{l}\text { Number of medications, } \\
\text { mean }\end{array}$ & 6.3 (min:0- max:21) & 3.6 \\
\hline Multimorbidity $(\%)$ & 362 (89.2) & - \\
\hline
\end{tabular}

\begin{tabular}{|c|c|c|}
\hline Measure & Total & SD \\
\hline Malnutrition 1 & $117(28.8 \%)$ & - \\
\hline Gait speed $(\mathrm{m} / \mathrm{s})$, mean & $0.84 \mathrm{~m} / \mathrm{s}(0-1,59 \mathrm{~m} / \mathrm{s})$ & 0.2 \\
\hline CST time (s), median & $13.4(\min 5.7-\max 36 / \mathrm{s})$ & 5.3 \\
\hline TUG (s), median & $11.4(\min 5-\max 36.7 / \mathrm{s})$ & 5.4 \\
\hline $\begin{array}{l}\text { HGS2 }(\mathrm{kg}) \text {, mean } \\
\text { HGS }(\mathrm{kg}) \text { female } \\
\text { HGS }(\mathrm{kg}) \text { male }\end{array}$ & $\begin{array}{l}24.2(\min 6-\max 52 \mathrm{~kg}) \\
20.7(\min 6-\max 40 \mathrm{~kg}) \\
32.2(\min 10-\max 52)\end{array}$ & $\begin{array}{l}8.1 \\
5.1 \\
8\end{array}$ \\
\hline SPPB score, mean & $9.3(\min 0-\max 12)$ & 3 \\
\hline $\begin{array}{l}\text { Balance test }{ }^{3} \\
\text { Side by side (able: } 0 \text { point, } \\
\text { unable: } 1 \text { point) }\end{array}$ & $\begin{array}{l}0 \text { point: } 392(93.6 \%) \\
1 \text { point: } 14(3.4 \%)\end{array}$ & $\begin{array}{l}- \\
-\end{array}$ \\
\hline $\begin{array}{l}\text { Semi tandem (able: } 0 \text { point, } \\
\text { unable: } 1 \text { point) }\end{array}$ & $\begin{array}{l}0 \text { point: } 380(93.6 \%) \\
1 \text { point: } 26(6.4 \%)\end{array}$ & - \\
\hline $\begin{array}{l}\text { Tandem (able: } 0 \text { point, unable: } \\
1 \text { point) }\end{array}$ & $\begin{array}{l}0 \text { point: } 71(17.5 \%) \\
1 \text { point: } 335(82.5 \%)\end{array}$ & - \\
\hline
\end{tabular}

1: Malnutrition status was determined from the MNA-SF using a cut-off of $\leq 11^{2}$ : Balance tests were dichotomized into unable and able to maintain for $10 \mathrm{~s},{ }^{3}$ : HGS cut offs were $<27 \mathrm{~kg}$ for men and $<16 \mathrm{~kg}$ for women, SPPB: Short physical performance battery, CST: Chair Stand test, TUG: Timed Up and Go test, HGS: Hand grip strength, SD: Standard deviation, min: Minimum, max: Maksimum, kg: Kilogram, MNA-SF: Mini Nutritional Assessment- short form balance test and HGS as static physical measures. Malnutrition was most associated with HGS and Tandem Balance test which were pointers of static performance. There was no significant association between TUG, 4-m Walk test and CST. Dynamic and static physical performance tests are used for assessment of muscle strength and muscle power. Although dynamic physical performance tests rely more on muscle power; static physical performance tests are associated more with muscle strength.

In our study, static physical performance tests were associated with malnutrition. Our study confirms previously reported connections between malnutrition and HGS and short physical performance battery $(9,10)$.

As we expected there was significant association between malnutrition and HGS cause of being direct measure of muscle function. There is a contradiction between HGS and malnutrition. Some authors have offered for the extra value of HGS in nutritional assessment (9). Furthermore, the result of a study that aimed to show effect of the nutritional supplementations on physical performance showed a significant improvement in HGS compared to other physical performance test (11). Despite that some previous studies showed that HGS may be of limited use as a predicting malnutrition $(12,13)$.

In this study, the tandem test as one of the standing balance tests was correlated with malnutrition status. A previous study found positive association between HGS and standing balance test, that both relies on muscle strength and it is explained by the differences between characteristics of muscle strength and muscle mass (14). Muscle strength is affected by neuromuscular system and measurement values are determined by neural, mechanical and muscular factors (15). Furthermore, the age appears to be more contributed to the decline of muscle strength rather than muscle mass (16).

On the other hand, there is still unclearness about the relationship between malnutrition and poor physical performance. Some previous papers fenced that muscle strength and muscle power were less strong associated compared to association of malnutrition and muscle mass $(17,18)$. Additionally, previous studies from Turkey showed significant relations between low scores of MNA and low skeletal Muscle Mass index in nursing homes residents (19), and sarcopenic males in nursing home (20).

Table 3. Correlation matrix of mini nutritional assesment and functional parameters (linear correlation)

\begin{tabular}{|c|c|c|c|c|c|c|c|}
\hline & $\begin{array}{l}\mathrm{Z} \text { balance } \\
\text { side by side }\end{array}$ & $\begin{array}{l}\mathbf{Z} \text { balance } \\
\text { semi tandem }\end{array}$ & $\mathrm{Z}$ balance tandem & $\begin{array}{l}\text { Z } \\
\text { CST }\end{array}$ & $\begin{array}{l}\text { Z } \\
\text { gait speed }\end{array}$ & $\begin{array}{l}\text { Z } \\
\text { TUG }\end{array}$ & $\begin{array}{l}\mathbf{Z} \\
\text { HGS }\end{array}$ \\
\hline$\beta(95 \% \mathrm{Cl})$ & $\begin{array}{l}0.008 \\
(-0.185,0.200)\end{array}$ & $\begin{array}{l}0.081(-0.092 \\
0.254)\end{array}$ & $\begin{array}{l}-0.128 \\
(0.002,0.254)\end{array}$ & $\begin{array}{l}-0.076 \\
(-0.274,0.122)\end{array}$ & $\begin{array}{l}0.071 \\
(-0.156,0.296)\end{array}$ & $\begin{array}{l}-0.016 \\
(-0.211,0.178)\end{array}$ & $\begin{array}{l}-0.134 \\
(-0.246,-0.023)\end{array}$ \\
\hline $\mathrm{p}$ & 0.938 & 0.35 & $0.046^{*}$ & 0.451 & 0.540 & 0.869 & $0.018^{*}$ \\
\hline
\end{tabular}


Lower muscle mass may cause mobility difficulties in malnourished patients which effects negatively to muscle strength and power and contributes to interference with physical activity (21). Otherwise some recent study' authors found that there was no association between muscle mass and physical performance measured by standing balance test (14).

MNA-SF was used to define malnutrition status in our study. There is no gold standard for screening of malnutrition. Prevalence of malnutrition can change cause of using different nutritional screening tools.

Our study showed malnutrition is associated with static physical performance rather than dynamic physical performance. Although a previous study advocated that malnutrition was most associated with dynamic physical performance (13). The authors argue that functional decline is associated not only with muscle strength also with muscle power. The fact that, muscle strength was found to be effected from neural, mechanical, muscular, metabolic problems as well as age rather than muscle mass (22). Addition to this elderly patient are more likely to have several multimorbidity and multisystem health problems as cognitive impairment, cardiological problems and joint function that can negatively effect on muscle strength.

The strength of this study was that nutritional and functional status were deeply analyzed by validated instruments in a comparatively large sample of Turkish older adults. Despite that, this study has some limitations. The participants were limited to the elderly with physical functional dependency, so the results of this study might not be generalizable to all Turkish older adults. Also, participants were only community outpatient, the home care dwellers and inpatient were not included which might also limit the generalizability. In this study we could not ignore the causative relationship that nutritional status influences the onset and the progress of a poor physical performance; on the other side, poor physical performance itself may provoke malnutrition.

Summering up, our results suggest that almost one third of elderly population was at nutritional risk. Malnutrition according to MNA-SF was mostly associated with static functionality measures. As a result, MNA-SF might be useful screening tool as a surrogate marker of functional status, especially if specific functionality testing cannot be applied; besides poor physical performance can provide information involved malnutrition state. Further studies are needed for a better understanding of the interaction between malnutrition status and different kinds of poor functional impairment in older people.

\section{Ethics}

Ethics Committee Approval: The study has been approved by Istanbul University, Istanbul Medical Faculty, Ethical Committee (approval no: 90767, date: 06.06.2020).
Informed Consent: The study is a retrospective study, no additional patient consent form has been created.

Peer-review: Internally peer-reviewed.

Financial Disclosure: The author declared that this study received no financial support.

\section{References}

1. Cederholm T, Barazzoni R, Austin P, Ballmer P, Biolo G, Bischoff SC, Compher C, Correia I, Higasgiguchi T, Holst M, Lensen GL, Malone A, Muscaritoli M, Nyulasi I, Pirlich M, Rothenberg E, Schindler K, Schneider SM, van der Schueren MAE, Sieber C, Valentini L, Yu JC, Gossum AV, Singer P. ESPEN guidelines on definitions and terminology of clinical nutrition. Clin nutr 2017;36:49-64.

2. Cederholm $T$, Jensen $G$, Correia $M$, Gonzalez MC, Fukushima $R$, Hihashiguchi T, Baptista G, Barazzoni R, Blaauw R, Coats A, Crivelli A, Evans DC, Gramlich L, Fuchs-Tarlovsky V, Keller H, Llido L, Malone A, Mogensen KM, Morley JE, Muscaritoli M, Nyulasi I, Pirlich M, Pisprasert $V$, van der Schueren MAE, Siltharm S, Singer P, Tappenden K, Velasco N, Waitzberg D, Yamwong P, Yu J, Gossum AV, Compher C, GLIM Core Leadership Committtee; GLIM Working Group. GLIM criteria for the diagnosis of malnutrition-a consensus report from the global clinical nutrition community. Clin Nutr 2019;38:1-9.

3. Volkert D. The role of nutrition in the prevention of sarcopenia. Wien Med Wochenschr 2011;161:409-415.

4. Guralnik JM, Branch LG, Cummings SR, Curb JD. Physical performance measures in aging research. J Gerontol 1989;44:M141-M146.

5. Wallace Jl, Schwartz RS, LaCroix AZ, UhImann RF, Pearlman RA. Involuntary weight loss in older outpatients: incidence and clinical significance. J am Geriatr Soc 1995;43:329-337.

6. Kiesswetter E, Pohlhausen S, Uhlig K, Diekmann R, Lesser S, Heseker H, Stehle $\mathrm{P}$, Sieber CC, Volkert D. Malnutrition is related to functional impairment in older adults receiving home care. J Nutr Health Aging 2013;17:345-350.

7. Rubenstein LZ, Harker JO, Salvà A, Guigoz $Y$, Vellas B. Screening for undernutrition in geriatric practice: developing the short-form mininutritional assessment (MNA-SF). J Gerontol A Biol Sci Med Sci 2001;56:M366-M372.

8. Barry E, Galvin R, Keogh C, Horgan F, Fahey $T$. Is the Timed Up and Go test a useful predictor of risk of falls in community dwelling older adults: a systematic review and meta-analysis. BMC geriatr 2014;14:14.

9. Flood A, Chung A, Parker H, Kearns V, O'Sullivan TA. The use of hand grip strength as a predictor of nutrition status in hospital patients. Clin Nutr 2014;33:106-114.

10. Tramontano A, Veronese N, Giantin V, Manzato E, Rodriguez-Hurtado D, Trevisan C, De Zaiacomo F, Sergi G. Nutritional status, physical performance and disability in the elderly of the Peruvian Andes. Aging Clin Exp Res 2016;28:1195-1201.

11. Veronese N, Stubbs B, Punzi L, Soysal P, Incalzi RA, Saller A, Maggi S. Effect of nutritional supplementations on physical performance and muscle strength parameters in older people: a systematic review and meta-analysis. Ageing Res Rev 2019;51:48-54.

12. Byrnes A, Mudge A, Young A, Banks M, Bauer J. Use of hand grip strength in nutrition risk screening of older patients admitted to general surgical wards. Nutr Diet 2018;75:520-526.

13. Ramsey $K A$, Meskers CG, Trappenburg MC, Verlaan S, Reijnierse EM, Whittaker AC, Maier AB. Malnutrition is associated with dynamic physical performance. Aging Clin Exp Res 2020;32:1085-1092.

14. Bijlsma AY, Pasma JH, Lambers D, Stijntjes M, Blauw GJ, Mesjers CGM, Maier $A B$. Muscle strength rather than muscle mass is associated with standing balance in elderly outpatients. J Am Med Dir Assoc 2013;14:493-498. 
15. Enoka RM. Muscle strength and its development. Sports medicine 1988;6:146-168.

16. Bischoff HA, Stahelin HB, Urscheler N, Ehrsam R, Vonthein R, Perrig-Chiello $P$, Tyndall A, Theiler R. Muscle strength in the elderly: its relation to vitamin D metabolites. Arch Phys Med Rehabil 1999;80:54-58.

17. Reijnierse EM, Trappenburg MC, Leter MJ, Blauw GJ, de van der Schueren MAE, Meskers CGM, Maier AB. The association between parameters of malnutrition and diagnostic measures of sarcopenia in geriatric outpatients. PloS one 2015;10:e0135933.

18. Bijlsma A, Meskers C, Van Den Eshof N, Westendorp RG, Sipila S, Stenroth L, Sillanpaa E, McPhee JS, Jones DA, Narici MV, Gapeyeva H, Paasuke M, Voit T, Barnouin Y, Hogrel JY, Butler-Browne G, Maier AB. Diagnostic criteria for sarcopenia and physical performance. Age (Dordr) 2014;36:275-285.
19. Tufan A, Bahat G, Ozkaya H, Taşcıoğlu D, Tufan F, Saka B, Akin S, Karan MA. Low skeletal muscle mass index is associated with function and nutritional status in residents in a Turkish nursing home. Aging Male 2016;19:182-186.

20. Bahat G, Saka B, Tufan F, Akin S, Sivrikaya S, Yucel N, Erten N, Karan MA. Prevalence of sarcopenia and its association with functional and nutritional status among male residents in a nursing home in Turkey. Aging Male 2010;13:211-214.

21. Alva MdCV, Camacho MEl, Velázquez JD, Lazarevich I. The relationship between sarcopenia, undernutrition, physical mobility and basic activities of daily living in a group of elderly women of Mexico City. Nutr Hosp 2013;28:514-521.

22. Clark BC, Manini TM. Sarcopenia $\neq$ dynapenia. J Gerontol A Biol Sci Med Sci 2008;63:829-834 